\title{
The quality of life of the elderly is negatively affected by pertrochanteric femoral fractures: a comparative study
}

\author{
Yüksel Uğur Yaradılmış®, Mustafa Caner Okkaoğlu®, Erdi Özdemirø, Ahmet Ateş®, İsmail \\ Demirkale $\odot$, Murat Altay $\odot$
}

Department of Orthopaedics and Traumatology, University of Health Sciences, Keçiören Health Practice and Research Center, Ankara, Turkey

\section{ABSTRACT}

Objectives: Limited data is available regarding the quality of life of hip fracture patients following surgery. This study examined the mid-term quality of life of hip fracture patients and compared these patients with healthy elderly patients devoid of hip fractures.

Methods: A total of 103 patients (aged $>65$ years) with pertrochanteric femoral fractures were treated with proximal femoral nail surgery in our clinic between January 2012 and December 2016. A healthy control group $(n=100)$ was demographically matched to the patients. The final follow-up visit included their Harris Hip Score and completion of a Short Form-36. The eight sub-parameters from the Short Form-36 form were also assessed.

Results: The mean follow-up time for the patients was $36.4 \pm 12.3$ (range, 24-72) months. The mean Charlson comorbidity score for the patient group was $4.4 \pm 2.1$ and the mean Harris Hip Score was $77.24 \pm 10.2$. The comparison of the Short Form-36 sub-parameters revealed that the quality of life of the patient group was found to be lower than that of the control group for the following parameters physical function, physical roles, vitality, and social function $(p<0.05)$.

Conclusions: Even if the fracture had healed of patients with hip fractures, QoL related to physical and social functions was not improved accordingly, new healthcare policies should be developed for these patients based on the premise that their physical capacity may not be fully regained. Moreover, the importance of hip fracture prevention was demonstrated by this study.

Keywords: Hip fracture, aged, quality of life, Short Form 36, morbidity

$\mathrm{H}$ ip fractures generally occur in patients aged $>65$ due to a low-energy trauma. These fractures constituted significant proportion traumas in elderly (aged $>65$ years) and account for $38 \%$ of all extremity fractures [1]. Approximately 2.3 million hip fractures per year are expected by 2050 owing to increased aging population [2]. Non-surgical treatment of hip fractures has high mortality rates [3]. Thus, surgical treatment is recommended as earlier as possible to mobilize the patients at the earliest convenience. It has been reported that patients who were operated due to a hip fracture in the first 48 hours and mobilized in the early period have significantly lower mortality rates $[4,5]$. In pertrochanteric fractures, osteosynthesis is the aim of the surgical treatment because of its metaphyseal location. Previous studies in the literature have 
shown high union rates and high hip scores with osteosynthesis of pertrochanteric fractures $[6,7]$.

Some patient dependent factors could negatively affect the healing following surgical treatment of hip fractures, such as the development of nutritional problems, dementia, or Alzheimer's disease, reduced mobilization capacity and prolonged hospitalization $[8$, 9]. Furthermore, elderly hip fracture patients have diminished ability to continue living independently which directly related to their hip scores. It remains unclear whether these patients can achieve a quality of life (QoL) equivalent to that of their peers despite a successful osteosynthesis of the hip fracture. Effective treatment for hip fracture patients should include physical, mental, and social improvement. Since some studies have reported a decrease in the physical, mental, and social aspects of their patients following hip fractures which lead to a decrease in patients' wellbeing. Thus, the reversibility of this decreased QoL deserves evaluation. However, the literature regarding this subject has conflicting results. Some studies have included a limited number of patients and short-term results, whereas other studies have provided few information regarding physical deterioration, mental, or social deterioration $[10,11]$. While a few studies of the musculoskeletal system diseases in Turkey have evaluated QoL issues, to the best of our knowledge, there has been no previous study that has evaluated the QoL for a morbid pathology such as a hip fracture.

This study examined the mid-term healing and improvement of the QoL in elderly patients following hip fractures and compared with a healthy matched population.

\section{METHODS}

\section{Patients and Study Design}

The patient records were examined for 167 elderly patients that were surgically treated for pertrochanteric femoral fracture in our clinic between January 2012 and December 2016. The design and protocol of this retrospective study were approved by the hospital Institutional Review Board (permit no: 4328876$929 / 20.02 .2020$ ). The study was conducted in accordance with the principles of the Declaration of Helsinki. This study included 103 patients who were aged $>65$ years and surgically treated with a proximal femoral nail (PFN). The patients excluded who could not be contacted during follow-up $(n=5)$, who were treated with a hemiarthroplasty $(\mathrm{n}=5)$, who were treated with dynamic hip screw (DHS) $(n=2)$, who were exitus during follow-up $(n=43)$, did not meet reduction criteria and had lag screw malpositioning (n $=5)$, nonunion and revision surgery $(\mathrm{n}=8 ; 4$ cut-out, 2 varus collapse, and 2 non-mechanical cause). A written informed consent was obtained from each patient. The demographic data and Charlson comorbidity scores of the patients were then recorded. The fractures were classified according to the $\mathrm{AO}$ classification system. The mean follow-up period was 36 months (range, 24-72 months). The overall mortality rate was determined to be $26 \%$. In $4(4 \%)$ patients had cut-out.

A control group $(n=100)$ was formed of randomly selected from patients aged $>65$ years who were living in the same geographic area without a hip pathology and matched to the patients via their demographic data. The patients were evaluated with the Harris Hip Score (HHS) and interviewed with the Short Form-36 (SF-36). The SF-36 form evaluates 8 sub-parameters, which includes physical function, physical role, bodily pain, general health, vitality, mental health, emotional role, and social function (Fig. 1). Then the physical, mental, and social QoL was evaluated by comparing the sub-parameters for the patients and the control group.

\section{Clinical Treatment and Surgical Techniques}

Mechanical and medical DVT prophylaxis was started immediately following admission to the hospital. Following the completion of the necessary preparations for anesthesia, surgery was performed as early as the general medical status of the patient allowed. Surgery was performed at a mean of 3.9 days (range, 1-9 days) following admission.

Infection prophylaxis was administered to all patients with i.v. cefazolin preoperatively. During the surgical procedure, initially closed reduction was tried under traction in the supine position. Closed reduction was often successful but $10(10 \%)$ patients required direct reduction maneuvers. The reduction quality was confirmed with fluoroscopy in the anteroposterior (AP) and lateral planes. The proximal femoral nail was implanted as previously described techniques [12]. The operation was ended following the final fluoroscopic confirmation of the fracture and the nail. 
Elderly pertrochanteric hip fracture

(All patients) $(n=167)$

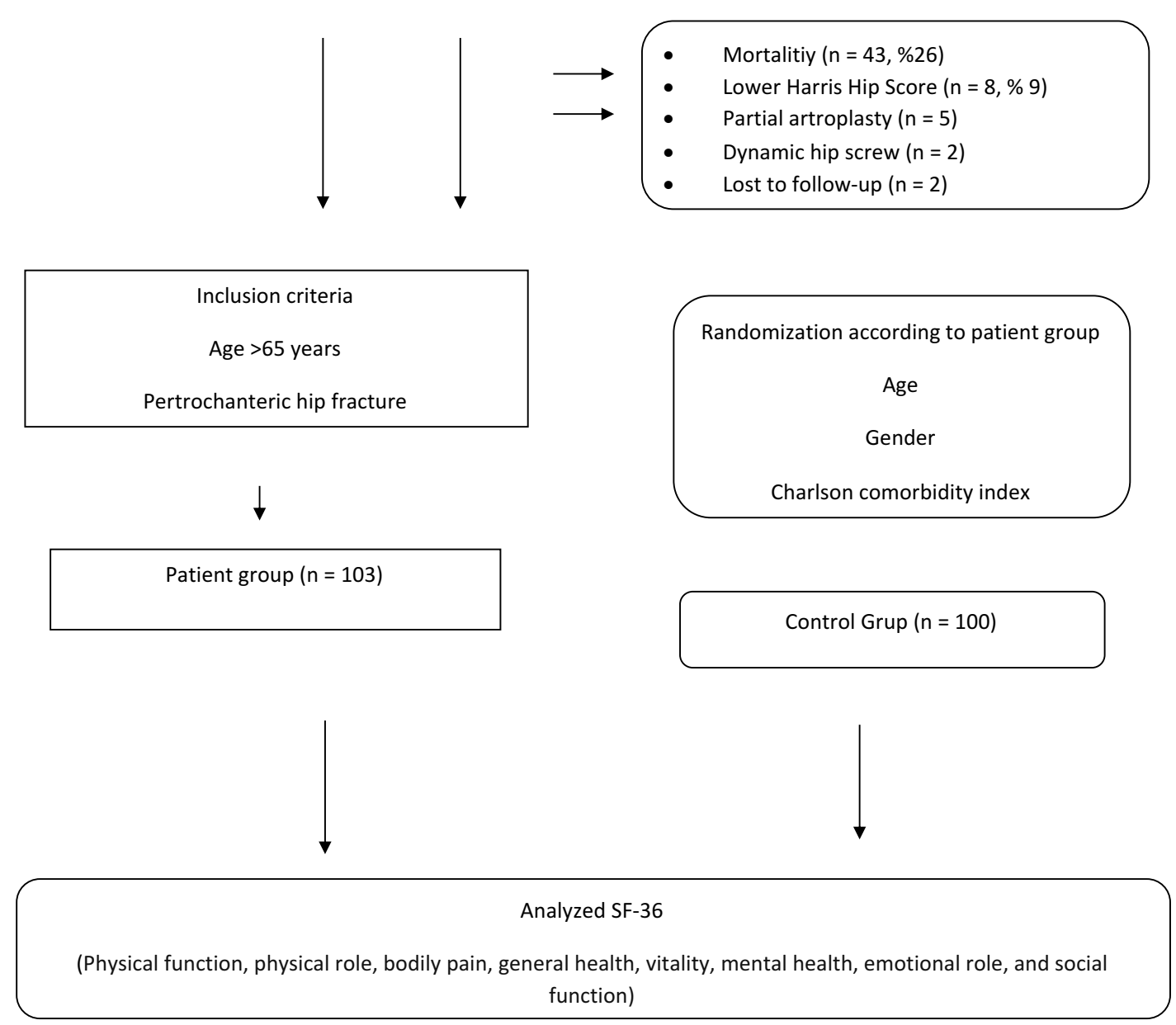

Fig. 1. Patients and study design

In the current study, two nailing systems, PFNA (Synthes GmbH, Oberdorf, Switzerland) or PTN (Biomet, Warsaw, Indiana, USA), were used. Varus malreduction of $<120 \mathrm{~mm}$ or displacement of $>10 \mathrm{~mm}$ was not accepted. The lag screw was placed at $<20 \mathrm{~mm}$ Baumgartner's tip-apex distance [13, 14]. One distal static interlocking screw was used in all patients.

\section{Follow-up}

The patients were mobilized with a walker on the postoperative first or second days. Weight-bearing was permitted as tolerated in all patients. Timing of full weight-bearing was decided based on fracture classification: at $6^{\text {th }}$ week for $\mathrm{A} 1$ and $\mathrm{A} 2$ fractures, at $12^{\text {th }}$ week for A3 fractures, respectively. The patients were followed-up with 2-week intervals until bone union occured and range of motion angles were noted. Patients with union continued to be followed up with annual controls. Bone nonunion and implant failure were checked radiologically. In the follow-up examinations, union and cut-out, cut-true, varus collapse, and lateral sliding were checked. At the final follow-up examinations, the patients were evaluated with the HHS and SF-36 $[15,16]$. The HHS system and a questionnaire SF-36 form. The HHS system incorporates a points system with 90-100 points indicating an excellent result, 80-89 points is good, 70-79 points are fair, and $<$ 70 points indicates a poor result.

\section{Statistical Analysis}

Data obtained in this study were analyzed statistically using SPSS v.22 software, and at a confidence 
interval of $95 \%$. Qualitative data were stated as the frequency distribution, and quantitative data were stated as the mean, minimum, and maximum values. Demographic data were evaluated with the Mann Whitney U-test. The HHS and the 8 sub-parameters of the SF 36 of the patients and control group were evaluated with the Mann Whitney U-test. A value of $p<0.05$ was accepted as statistically significant.

\section{RESULTS}

The mean age of the subjects was $75.2 \pm 12$ years (range, 65-93 years) in the patient group and $73.4 \pm$ 10.4 years (range, 65-90 years) in the control group. The gender ratio $(\mathrm{F} / \mathrm{M})$ was $2 / 1$ for both the patient and control groups. The mean Charlson comorbidity score was $4.4 \pm 2.1$ (range, 1-7) in the patient group and $4.1 \pm 1.9$ (range, 1-6) in the control group. According to the AO classification, $44 \%$ of the fractures were AO 31A $1,34 \%$ were AO $31 \mathrm{~A} 2$, and $23 \%$ were AO 31A 3. No statistically significant differences were found between the patient and control groups with respect to their demographic data $(p>0.05)$ (Table 1).
The mean follow-up time for the patients was 36.4 \pm 12.3 (range, 24-72) months. The mean of union 3.3 \pm 1.8 months. The HHS scores of the patients were excellent-good in $55.4 \%$ of patients, fair in $36 \%$ and poor in $\% 8$ of patients in this study. The mean HHS for all of the patients was $77.2 \pm 10.2$.

The SF-36 scores of the patients were evaluated for 3 health parameters and 8 sub-parameters. The mean scores in patients group were calculated as physical function $33.6 \pm 24.9$, physical role $23.6 \pm 27.9$, bodily pain $63.8 \pm 21.5$, general health $44.9 \pm 17.4$, vitality $36.8 \pm 19.2$, mental health $57.5 \pm 15.2$, emotional role $43.9 \pm 39.1$, and social function $56.8 \pm 24.1$. The mean SF-36 scores in patients and control group are shown in Fig. 2.

In the comparison of the SF-36 sub-parameters, the QoL of the patient group was observed to be lower than that of the control group in respect to physical function, physical role, vitality, and social function $(p$ $<0.001, p<0.001, p=0.032, p=0.045$, respectively). The 3 health parameters, physical health, general health, and mental health were significantly lower in the patient group than in the control group $(p<0.05)$. The SF-36 data for both groups are shown in Table 2.

Table 1. Demographic data of the patients and the control group

\begin{tabular}{|c|c|c|c|}
\hline & $\begin{array}{c}\text { Elderly Hip } \\
\text { Fractures } \\
(\mathbf{n}=\mathbf{1 0 3})\end{array}$ & $\begin{array}{l}\text { Control Group } \\
\quad(\mathbf{n}=\mathbf{1 0 0})\end{array}$ & $p$ value \\
\hline Age (years), mean \pm SD (range) & $75.2 \pm 12(65-93)$ & $73.4 \pm 10.3$ & 0.765 \\
\hline \multicolumn{4}{|l|}{ Gender } \\
\hline Male & 38 & 35 & 0.346 \\
\hline Female & 65 & 65 & \\
\hline \multicolumn{4}{|l|}{ Side } \\
\hline Right & 54 & & \\
\hline Left & 49 & & \\
\hline \multicolumn{4}{|l|}{ AO 31A classification } \\
\hline Type 1 & 50 & & \\
\hline Type 2 & 40 & & \\
\hline Type 3 & 13 & & \\
\hline $\begin{array}{l}\text { Charlson comorbidity index, } \\
\text { mean } \pm \text { SD (range) }\end{array}$ & $4.4 \pm 2.1(1-7)$ & $4.1 \pm 1.9(1-6)$ & 0.612 \\
\hline Mean of union time (months), mean \pm SD & $3.3 \pm 1.8$ & & \\
\hline Harris hip score, mean \pm SD & $77.2 \pm 10.2$ & & \\
\hline
\end{tabular}




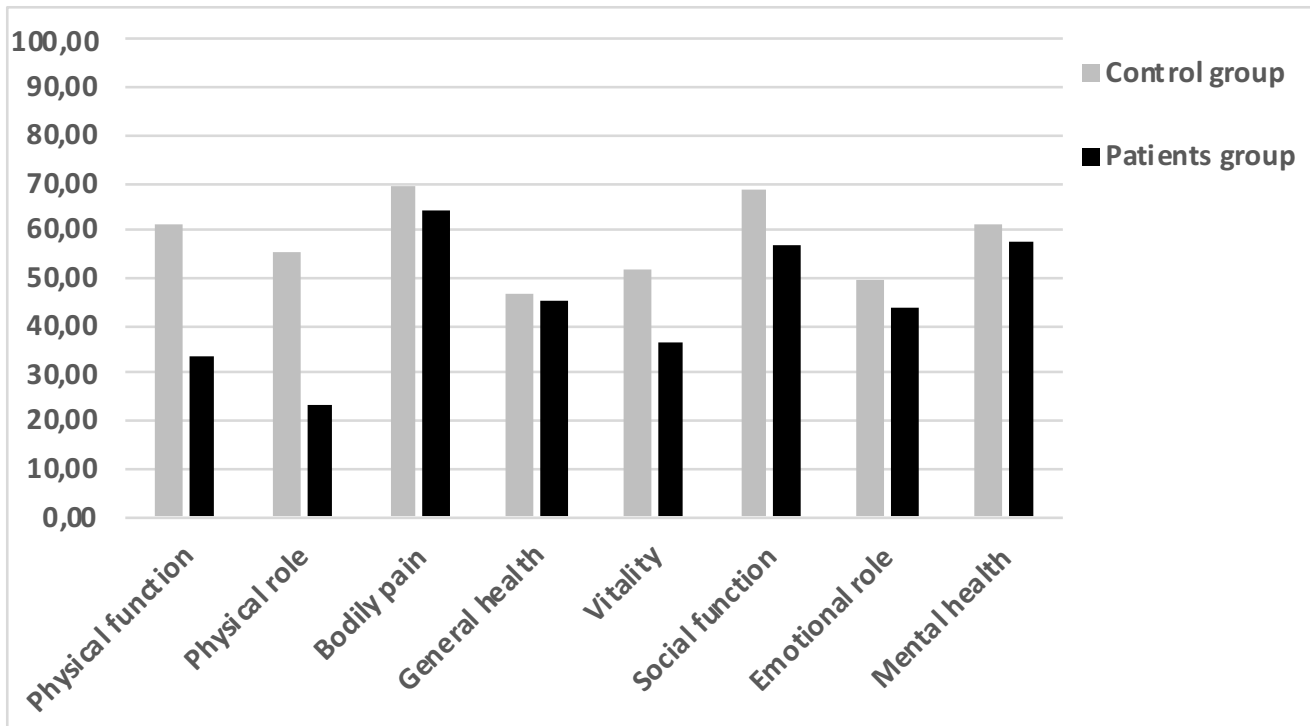

Fig. 2. SF-36 subtype-parameter data for the patients and control groups.

\section{DISCUSSION}

Non-union is a rare problem (1-2\%) following pertrochanteric fractures, and generally successful HHS points are obtained with surgical treatment at a high rate $(85-90 \%)$ [17]. Nevertheless, higher union rates and higher hip scores do not mean that the patients are completely healed. Thus, in addition to obtaining a bony union, the main aim should be regaining independent mobility and improvement of QoL. The surgical outcomes (HHS) of the current study were favorable in most cases; however, the QoL of the patients had not improved. The changes in physical, general, and mental QoL were examined in patients who obtained high hip scores and then compared with a normative population. In this study, the values for physical function, social function, and vitality in the elderly with hip fractures were significantly reduced compared to the control group. Moreover, even if the fracture had healed, QoL related to physical and social functions was not improved accordingly.

QoL questionnaires can be generic or disease-specific. Examples of generic questionnaires are the Nottingham Health Profile, the Sickness Impact Profile (SIP), Short Form 36 of the Medical Outcomes Study (SF-36), and the EuroQol (EQ-5D) [14, 18]. The SF36 was published by Ware and Sherbourne, and selects 8 areas of health from a list of 40 , in collaboration with the RAND Corporation [14]. This evaluation of 36 items of 8 subtypes consists of physical function (10 items), social function ( 2 items), physical role difficulty (4 items), emotional role ( 3 items), mental health

Table 2. Comparison of the SF-36 subtype-parameter data from the patients and the control group

\begin{tabular}{lccc}
\hline & Elderly Hip Fracture & Control Group & $\boldsymbol{p}$ value \\
\hline Physical function & $33.5 \pm 24.9$ & $61.2 \pm 24.9$ & $\mathbf{0 . 0 0 0}$ \\
Physical role & $23.6 \pm 27.9$ & $55.5 \pm 27.9$ & $\mathbf{0 . 0 0 0}$ \\
\hline Bodily pain & $63.8 \pm 21.5$ & $69.1 \pm 21.5$ & 0.231 \\
General health & $44.9 \pm 17.4$ & $46.4 \pm 17.4$ & 0.710 \\
Vitality & $36.8 \pm 19.2$ & $52.1 \pm 19.2$ & $\mathbf{0 . 0 3 2}$ \\
Social function & $56.8 \pm 24.1$ & $68.8 \pm 24.1$ & $\mathbf{0 . 0 4 5}$ \\
\hline Emotional role & $43.9 \pm 39.1$ & $49.9 \pm 39.1$ & 0.344 \\
Mental health & $57.5 \pm 15.2$ & $61.1 \pm 15.2$ & 0.634 \\
\hline
\end{tabular}


(5 items), energy/vitality (4 items), pain ( 2 items), and perception of general health (5 items). Reliability studies have been conducted for the Turkish version of the SF-36, and the Cronbach alpha coefficients were calculated for each subscale [19].

Musculoskeletal system diseases such as lower extremity arthritis, lumbar pathologies, and spinal deformities in the elderly could diminish the QoL of patients because they often lead to immobilization. Hellberg et al. [20] reported that hip and vertebral osteoporotic fractures can cause a decrease in predicted QoL while upper extremity osteoporotic fractures found not to be related decreased QoL. Rohde et al. [18] examined the impact of hip fractures on healthrelated and global QoL and they observed a significant decrease in the QoL. They emphasized the importance of the prevention of hip fractures [18]. Peterson et al. [10] observed a decrease in the physical role in a 1year evaluation of $38 \mathrm{hip}$ fracture patients. While this study did not use a control group for comparison, the return to previous physical activity level rate was reduced, and a significant change was observed in other SF-36 parameters [10]. In a study reporting the first year SF-36 scores of 62 hip fracture patients by Giessauf et al. [11], $63 \%$ of the patients had excellent or good results. However, they observed an increased bodily pain, and diminished social functioning, and mental health subscales and two summary scores (physical and mental component of SF-36) [11]. The absence of QoL of patients prior to the fracture makes it challenging to compare QoL values. Furthermore, retrospective scoring was not recommended if the national SF-36 was used or there was no control group [21]. A strong aspect of the current study was the selection of the control group from the same social region, matched demographic data of the patient group.

Koval et al. [22] showed that the type of fracture surgery was not a major factor affecting the healing but the age ( $>85$ years) of the patient and the pre-fracture mobility capacity were the important factors. Fox et al. [23] found that mobility prior to discharge, prolonged hospital stay, age, and male gender were directly influence the healing of hip fractures. In the same study, prolonged hospital stay was also shown to cause wound infections and pressure ulcers. In the current study, risk groups for poor results were not evaluated [23].

\section{Limitations}

There are some limitations of the current study. Negative factors that affect QoL were not evaluated, and therefore further research is required. Furthermore, a prospective study would be more enlightening, by acknowledging the difficulty in obtaining the pre-fracture status of the patients. Future studies could make a more systematic evaluation of elderly patients by making comparisons with other musculoskeletal system diseases.

\section{CONCLUSION}

In conclusion, the results of this study showed that the physical, social, and vitality parameters of patients with hip fractures was lower than control group; thus, negatively affecting their QoL despite successful surgery. New healthcare policies should be developed for these patients considering their physical capacity may not be fully regained. In addition, this study has demonstrated the importance of taking precautions to prevent hip fractures before the need arises for the treatment of hip fractures in elderly patients.

\section{Authors' Contribution}

Study Conception: YUY, MCO; Study Design: YUY; Supervision: EÖ; Funding: EÖ; Materials: YUY, AA; Data Collection and/or Processing YUY, MCO; Statistical Analysis and/or Data Interpretation: YUY; Literature Review: ID; Manuscript Preparation: YUY and Critical Review: MA.

\section{Conflict of interest}

The authors disclosed no conflict of interest during the preparation or publication of this manuscript.

\section{Financing}

The authors disclosed that they did not receive any grant during conduction or writing of this study.

\section{REFERENCES}

1. Baron JA, Karagas M, Barrett J, Kniffin W, Malenka D, Mayor $\mathrm{M}$, et al. Basic epidemiology of fractures of the upper and lower limb Measuring Recovery After a Hip Fracture 301 among Americans over 65 years of age. Epidemiology 1996;7:612-8.

2. Gullberg B, O Johnell, Kanis JA. World-wide projections for 
hip fracture. Osteoporosis Int 1997;7:407-13.

3. Johns WL, Strong B, Kates S, Patel NK. POSSUM and P-POSSUM scoring in hip fracture mortalities. Geriatr Orthop Surg Rehabil 2020;11:2151459320931674.

4. Kuru T, Olçar HA. Effects of early mobilization and weight bearing on postoperative walking ability and pain in geriatric patients operated due to hip fracture: a retrospective analysis. Turk J Med Sci 2020;50:117-25.

5. Moja L, Piatti A, Pecoraro V, Ricci C, Virgili G, Salanti G, et al. Timing matters in hip fracture surgery: patients operated within 48 hours have better outcomes. A meta-analysis and metaregression of over 190,000 patients. PloS One 2012;7:e46175.

6. Karakoyun Ö, Erol M, Küçükkaya M, Demirok M. Intertrochanteric femoral fractures treatment with proximal femoral nail. Int J Basic Clin Med 2014;1;165-70.

7. Albayrak A, Bayrak SK, Duramaz A, Kızılkaya C, Seller A, Aslantaş FÇ. [Demographic and clinical results of proximal femoral fractures]. Acta Medica Alanya 2017;1:145-8. [Article in Turkish]

8. Müller M, Seitz A, Besch L, Hilgert RE, Seekamp A. [Proximal femur fractures: results and complications after osteosynthesis with PFN and TGN]. Unfallchirurg 2008;111:71-7. [Article in German]

9. Kalem M, Kocaoğlu H, Şahin E, Kocaoğlu MH, Başarır K, Kınık H. Impact of echocardiography on one-month and one-year mortality of intertrochanteric fracture patients. Acta Orthop Traumatol Turc 2018;52:97-100.

10. Peterson MGE, Allegrante JP, Cornell CN, MacKenzie CR, Robbins L, Horton R, et al. Measuring recovery after a hip fracture using the SF-36 and Cummings scales. Osteoporosis Int 2002;13;296-302.

11. Giessauf C, Glehr M, Bernhardt GA, Seibert FJ, Gruber K, Sadoghi P, et. al. Quality of life after pertrochanteric femoral fractures treated with a gamma nail: a single center study of 62 pa tients. BMC Musculoskelet Disord 2012;13:214.

12. Yaozeng X, Dechun G, Huilin Y, Guangming Z, Xianbin W. Comparative study of trochanteric fracture treated with the prox- imal femoral nail anti-rotation and the third generation of gamma nail. Injury 2010:41;1234-8

13. Fogagnolo F, Kfuri M Jr, Paccola CA. Intramedullary fixation of pertrochanteric hip fractures with the short AO-ASIF proximal femoral nail. Arch Orthop Trauma Surg 2004;124:31-7.

14. Baumgaertner MR, Solberg BD. Awareness of tip-apex distance reduces failure of fixation of trochanteric fractures of the hip. J Bone Joint Surg Br 1997:79:969-71.

15. Harris WH. Traumatic arthritis of the hip after dislocation and acetabular fractures: treatment by mold arthroplasty. An end-result study using a new method of result evaluation. J Bone Joint Surg Am 1969;51:737-55.

16. Ware JEJ, Sherbourne CD. The MOS 36-item short-form health survey (SF-36). I. Conceptual framework and item selection. Med Care 1992;30:473-83.

17. Baumgaertner M. Intertrochanteric hip fractures, Skeletal Trauma 2003;2:1776-816.

18. Rohde G, Haugeberg G, Mengshoel AM, Moum T, Wahl AK. Two-year changes in quality of life in elderly patients with lowenergy hip fractures. A case-control study. BMC Musculoskelet Disord 2010;11:226.

19. Demiral Y, Ergor G, Unal B, Semin S, Akvardar Y. Normative data and discriminative properties of short form 36 (SF-36) in Turkish urban population. BMC Public Health 2006;6:247.

20. Hallberg I, Rosenqvist AM, Kartous L, Löfman O, Wahlström O, Toss G. Health-related quality of life after osteoporotic fractures. Osteoporos Int 2004; 15:834-41.

21. Scholten AC, Haagsma JA, Steyerberg EW, van Beeck EF, Polinder S. Assessment of pre-injury health-related quality of life: a systematic review. Popul Health Metr 2017;15:10.

22. Koval KJ, Skovron ML, Aharonoff GB, Zuckerman JD. Predictors of functional recovery after hip fracture in the elderly. Clin Orthop 1998;348:22-8.

23. Fox HJ, Pooler J, Prothero D, Bannister GC. Factors affecting the outcome after proximal femoral fractures. Injury 1994;25;297-300. 